\title{
Selective Elimination of Hypothalamic Neurons by Grafted Hypertension-inducing Neural Tissue
}

\author{
R. Eilam, R. Malach, and M. Segal \\ Department of Neurobiology, Brain Research Building, The Weizmann Institute, Rehovot, 76100 Israel
}

\begin{abstract}
Embryonic hypothalamic tissue originating from spontaneously hypertensive rats (SHR) was implanted in young normotensive Wistar Kyoto rats in an attempt to localize hypothalamic regions directly responsible for the induction of hypertension. A $25 \%$ increase in host systolic blood pressure as compared with the controls was recorded 3 months after implantation in the animals receiving rostral hypothalamic tissue (R-SHR), whereas blood pressure was not affected in the animals grafted with caudal hypothalamic tissue (C-SHR). The hypertension in the R-SHR group was accompanied by hypertrophy of the heart and kidneys.

The number of vasopressin-immunopositive (VPi) parvocellular cells in the hypothalamic paraventricular nucleus (PVN) of the R-SHR group was massively reduced (by $72 \%$ ), while that of the tyrosine hydroxylase-immunopositive cells displayed no change. In the suprachiasmatic nucleus of these animals the VPi cell number was unaltered. In the C-SHR, the amount of parvocellular VPi cells was also unaltered. Likewise, oxytocin-containing cells were the same in all groups. DNA nick-end labeling of the tissue revealed that PVN cells are undergoing programmed cell death. These results implicate a selective degeneration by hypothalamic PVN cells in the pathogenesis of hypertension.
\end{abstract}

IKey words: hypothalamic graft, cell degeneration, hypertension, parvocellular cells, vasopressin-immunopositive cells, programmed cell death]

The likelihood that the brain undergoes severe morphological changes during the development of hypertension is indicated by a marked loss in brain weight and volume in spontaneously hypertensive rats (SHR) (Nelson and Boulant, 1981; Bendel and Eilam, 1992). The regulation of blood pressure is maintained through interactions among several central and peripheral mechanisms. The hypothalamus (HTH) is a central structure that integrates autonomic and neuroendocrine information (Swanson and Sawchenko, 1983). Both the rostral and caudal HTH regions play a major role in blood pressure regulation (Ciriello and Calaresu, 1980; Xiao and Brezenoff, 1988). Genetic hypertension in rats is associated with structural and neurochemical alterations that develop gradually in various hypo-

Received Aug. 10, 1993; revised Feb. 3, 1994; accepted Feb. 16, 1994.

We thank Dr. V. Lavie for her advice regarding the photographic work, Dr. M. Castel for her monoclonal oxytocin antibodies, and Dr. E. Schechtman for the statistical analysis. This work was supported, in part, by the Israel Academy of Science and Humanities, the Israel Institute for Psychobiology-Charles E. Smith Foundation, the Israeli Ministry of Health, and the Pearl Levine Foundation for Research in the Neurosciences.

Correspondence should be addressed to Dr. R. Eilam, Department of Neuro biology, Brain Research Building. The Weizmann Institute, Rehovot 76100, Israel Copyright (C) 1994 Society for Neuroscience $0270-6474 / 94 / 144891-12 \$ 05.00 / 0$ thalamic regions; the basic levels of adrenergic amines, such as epinephrine and norepinephrine in the caudal HTH (Nagaoka and Lovenberg, 1977; Winternitz et al., 1984), as well as of angiotensin II in the rostral HTH (Meyer et al., 1990), are higher in the SHR than in the normal strain. On the other hand, far lower brain levels of vasopressin (VP) and oxytocin (OT) have been measured in the rostral HTH region of the hypertensive rats than in the normal strain (Morris and Keller, 1982). Quantitation of cell size and cell density during the maturation process has revealed significant changes in the paraventricular and supraoptic nuclei (located in the rostral hypothalamus) in the SHR compared with normotensive rats (Fukushima et al., 1968; Nelson and Boulant, 1979). Interestingly, SHR were found to display brain ventricular enlargement during the same period (Bendel and Eilam, 1992). It is still unclear whether these modifications play a causal role in inducing hypertension.

In a previous study (Eilam et al., 1991), we have shown that adult normotensive Wistar Kyoto (WKY) rats are rendered hypertensive when grafted with tissue taken from the HTH of SHR embryos, results that were confirmed by Murphy et al. (1991). In the present study, we explore the physiological and morphological consequences of transplants of rostral and/or caudal regions of the HTH of SHRs in normotensive rats.

\section{Materials and Methods}

Transplantation. Pregnant dams were killed by cervical dislocation. Their 15-d-old embryos were dissected out under sterile conditions and placed in an oxygen-enrich, chilled L15 solution. The HTH was separated from the septal area by a coronal cut at the level of the chiasma, from the midbrain by a coronal incision at the level of the mammillary bodies, and from the pyriform cortex and ventral forebrain by two sagittal sections. The isolated HTH was divided into rostral and caudal regions at the level of the zona incerta and each segment was removed separately (see Results).

Eight-week-old WKY rats were grafted with $3 \mu$ l of either rostral or caudal embryonic SHR hypothalamic tissue (R-SHR and C-SHR, respectively) aiming at the bottom of the third ventricle (Eilam et al., 1991). In order to obtain volumes approaching those of a whole HTH, two rostral or two caudal segments were used for each implantation. The controls consisted of (1) WKY rats implanted with embryonic rostral WKY HTH tissue (R-WKY), (2) WKY rats receiving caudal WKY HTH tissue (C-WKY), (3) WKY rats grafted unilaterally-approximately $1 \pm 0.1 \mathrm{~mm}$ to the left of the third ventricle-with rostral SHR HTH tissue, (4) WKY rats grafted unilaterally (as group 3) with caudal SHR HTH tissue, (5 and 6) sham-operated (i.e., needle aimed at the third ventricle) WKY and SHR rats, respectively.

Systolic blood pressure. Systolic blood pressure (SBP) was measured by tail plethysmography in conscious rats. Recordings were taken with a pneumatic pulse transducer, connected to a physiograph. The mean SBP is presented as the average of four measurements for each rat.

Body, heart, and kidney weight. At different times postimplantation the animals were weighed, anesthetized, and perfused with $4 \%$ para- 

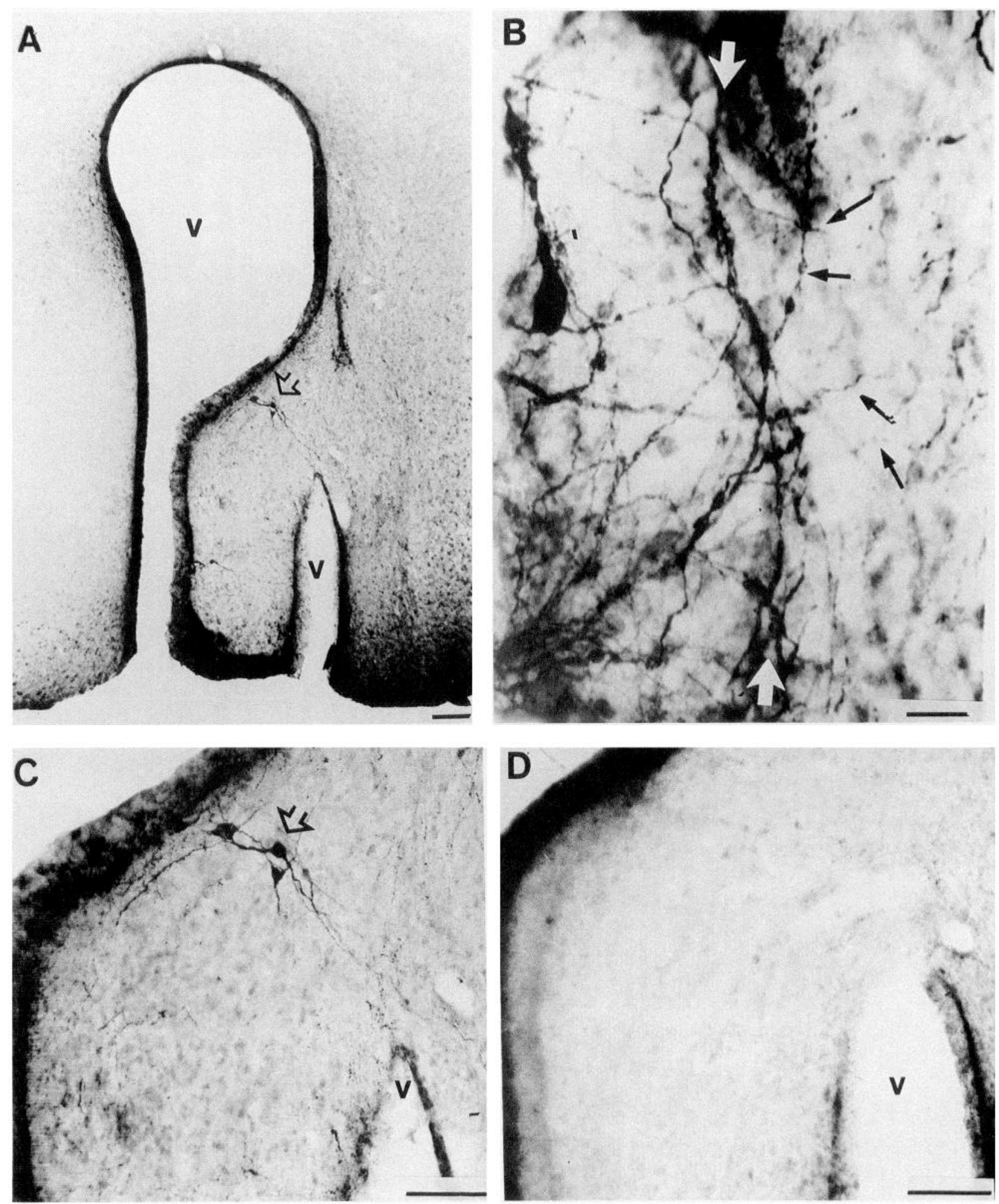

Figure 1. Low $(A)$ and high $(B-D)$ magnifications of OTi- $(A-C)$ and VPi $(D)$-stained sections taken from a rostral graft located in the third ventricle, 3 months after implantation. The OTi cells show abundant sprouting of fibers. No VPi cells are visible in the graft $(D)$. $B$, High magnification of section of OTi cells, showing some of the fibers crossing the graft borders (white arrows) and penetrating into the hypothalamic parenchyme of the host (black arrows). $V$, third ventricle. Scale bars: $A, C$, and $D, 100 \mu \mathrm{m} ; B, 25 \mu \mathrm{m}$.

formaldehyde in phosphate-buffered saline. The hearts and kidneys were then excised, washed with saline, blotted, and weighed.

Immunohistochemistry. Paraformaldehyde (4\%)-perfused brains of 2 ,

3 , and 8 month implanted rats were removed and stored for $5-14 \mathrm{~d}$ in

$1 \%$ formaldehyde. Serial $50 \mu \mathrm{m}$ coronal (vibratome) sections of the implanted regions were submitted to an immunohistochemistry procedure, using a technique described previously (Eilam et al., 1991). Alternate sections were stained for VP and tyrosine hydroxylase (TH) (polyclonal antisera, 1:3000 dilution for both; Incstar Corp., Stillwater, $\mathrm{MN}$ ) or for OT (monoclonal antiserum, 1:50). Preincubation overnight 

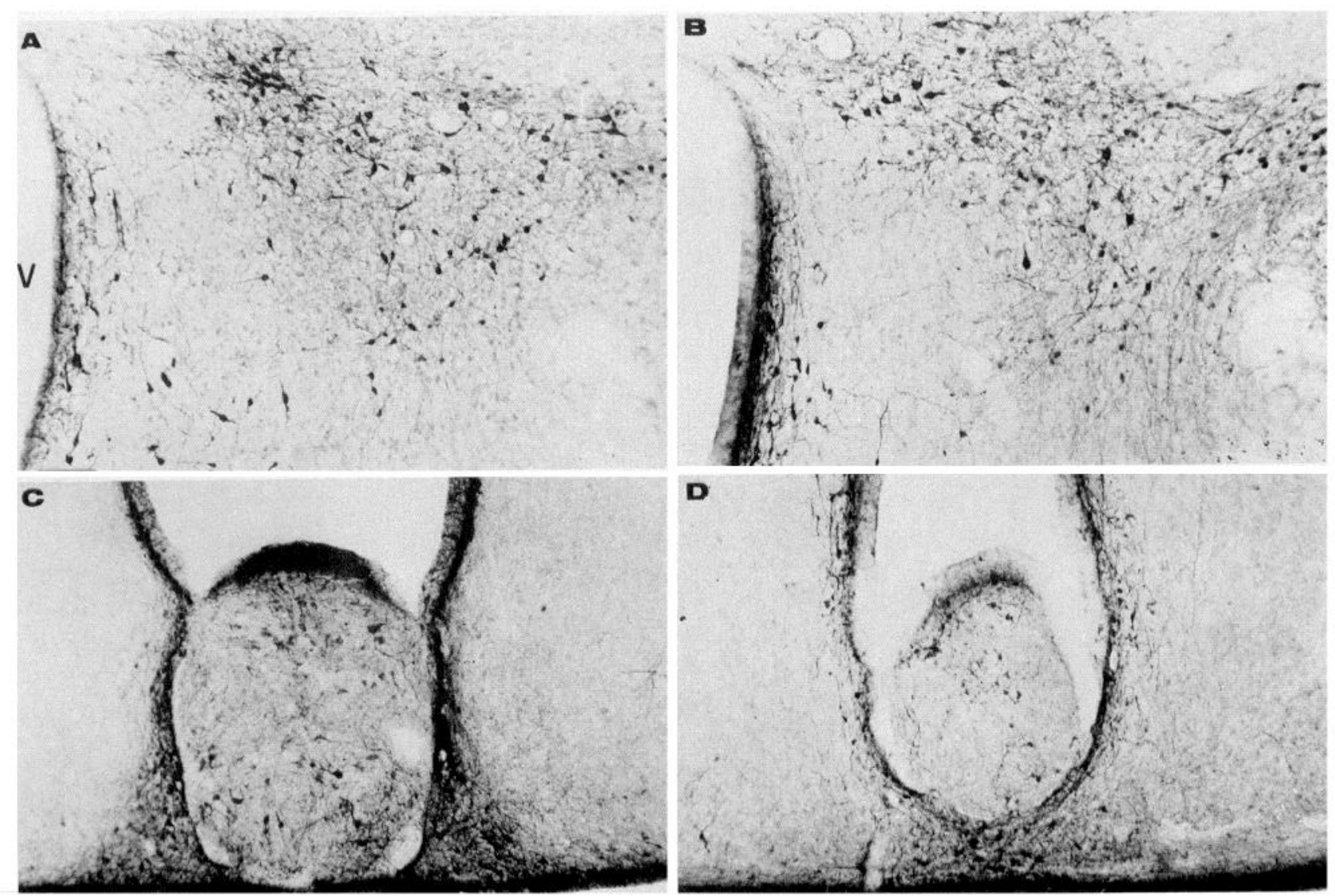

Figure 2. Bright-field photomicrograph of coronal sections stained for THi. The sections are taken from grafted rats (C-SHR, $A$ and $C$; R-SHR, $B$ and $D$ ) 8 months postimplantation. $A$ and $B$, Low-power magnification illustrating the posterior region of the paraventricular nucleus of the grafted rats. No change in the number of THi was noticed in the PVN of the grafted animals. $C$ and $D$, Grafts located at the bottom of the third ventricle. $V$, third ventricle. C-SHR and R-SHR, WKY rats grafted with caudal or rostral (respectively) hypothalamic tissue taken from SHR embryos. Scale bar (in $A$ ), $100 \mu \mathrm{m}$ (for $A-D$ ).

with synthetic VP $(1: 100 \mu \mathrm{g} / \mathrm{ml})$ or OT $(1: 200 \mu \mathrm{g} / \mathrm{ml})$ of selected sections from different levels (i.e., anterior commissural nucleus, anterior PVN, and medial PVN) completely eliminated staining in control sections. The OT antigen was rat posterior pituitary solubilate (Ben-Barak et al., 1985), which is an unequivocal anti-oxytocin-neurophysin in all dilutions. In our experimental conditions, the vasopressin antibody recognized mainly vasopressin-neurophysin [but it did cross-react with OT-neurophysin at 1:500 dilution, which we avoided or with different fixations, i.e., mixture of paraformaldehyde $(1 \%)$ with glutaraldehyde $(2.5 \%)]$.

Nissl staining. Three months postimplantation, alternate brain sections $(25-35 \mu \mathrm{m})$ of R-SHR and control animals were stained for Nissl (and also for vasopressin). Stained somata containing clearly visible nuclei in the various regions of the paraventricular nucleus (PVN) were counted under a light microscope $(\times 250-1000)$ in both the experimental and control groups.

Cell counts. The PVN was divided into three magno- and five parvocellular regions (Swanson et al., 1981; Sawchenko and Swanson, 1982). The cells in the various regions were counted according to their type, using a light microscope at high-power magnification $(\times 250-1000)$. The VP- and TH-immunopositive (VPi and $\mathrm{THi}$, respectively) or VPi OTimmunopositive (OTi)-stained cells were counted in alternate sections. Double counting errors were corrected according to the method of Abercrombie (1946).

Terminal deoxynucleotidyl transferase (TdT)-mediated dUTP-biotin nick-end labeling (TUNEL) (Gavrieli et al., 1992, with some modifications). Floating vibratome sections were stripped of protein by incubation with $20 \mu \mathrm{g} / \mathrm{ml}$ proteinase K (Sigma Chemical Co.) for $15 \mathrm{~min}$; sections were then washed four times in Tris-buffered saline (TBS; pH 7.2). The sections were mounted on slides (without drying!) and each

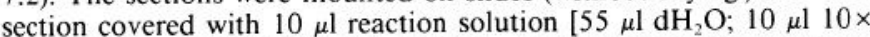
RX buffer, $2 \mu \mathrm{l}$ TdT (30 U), $10 \mu \mathrm{l} 0.025 \mathrm{M} \mathrm{CoCl}_{2}$ (TdT kit from Kodak,
New Haven, CT); $20 \mu \mathrm{l} 0.5 \mathrm{~mm} \mathrm{Bi-21-dUTP} \mathrm{(Clonetech} \mathrm{Laboratories}$ Inc., Palo Alto, CA)] and incubated in a humid box at $37^{\circ} \mathrm{C}$ for $60 \mathrm{~min}$. The reaction was terminated by rinsing the sections thoroughly in TBS. The sections were then incubated for an additional $1 \mathrm{hr}\left(37^{\circ} \mathrm{C}\right)$ with FITC-extra-avidin solution (1:20; Biomakor, Rehovot, Israel).

Statistical analyses. Cell counts were compared by one-way analysis of variance (ANOVA) for each of the time periods. The data were analyzed using logarithmic transformation (to obtain groups with similar variances). ANOVA was followed by Fisher's LSD multiple comparison procedure. Blood pressure differences among groups were analyzed by means of the Duncan test. The other results were compared using the paired and unpaired Student's $t$ test when appropriate. The results are presented as mean \pm SEM

\section{Results}

Examination of the sections of the grafted animals revealed intergroup variations in graft size. The maximal ventral-dorsal length varied between 390 and $840 \mu \mathrm{m}$, and the anterior-posterior extent ranged between 500 and $850 \mu \mathrm{m}$. The rostral grafts contained some VPi, OTi, and THi cells (Figs. 1,2); their caudal counterparts; on the other hand, lacked VPi and OTi cells, but were richer in THi neurons and fibers. These findings confirmed that the regions harvested from the fetal tissue were reliably separated into rostral and caudal segments.

Although the systolic blood pressurc (SBP) of the R-SHR increased considerably during the 8 month postoperative period, it invariably remained below that of the sham-operated SHR animals (Fig. 3). In the C-SHR, SBP did not change sig- 
Figure 3. Changes in mean SBP $( \pm$ SEM $)$ as a function of time postimplantation. The letters designate significantly different subgroups $(p<0.01$, Duncan test).

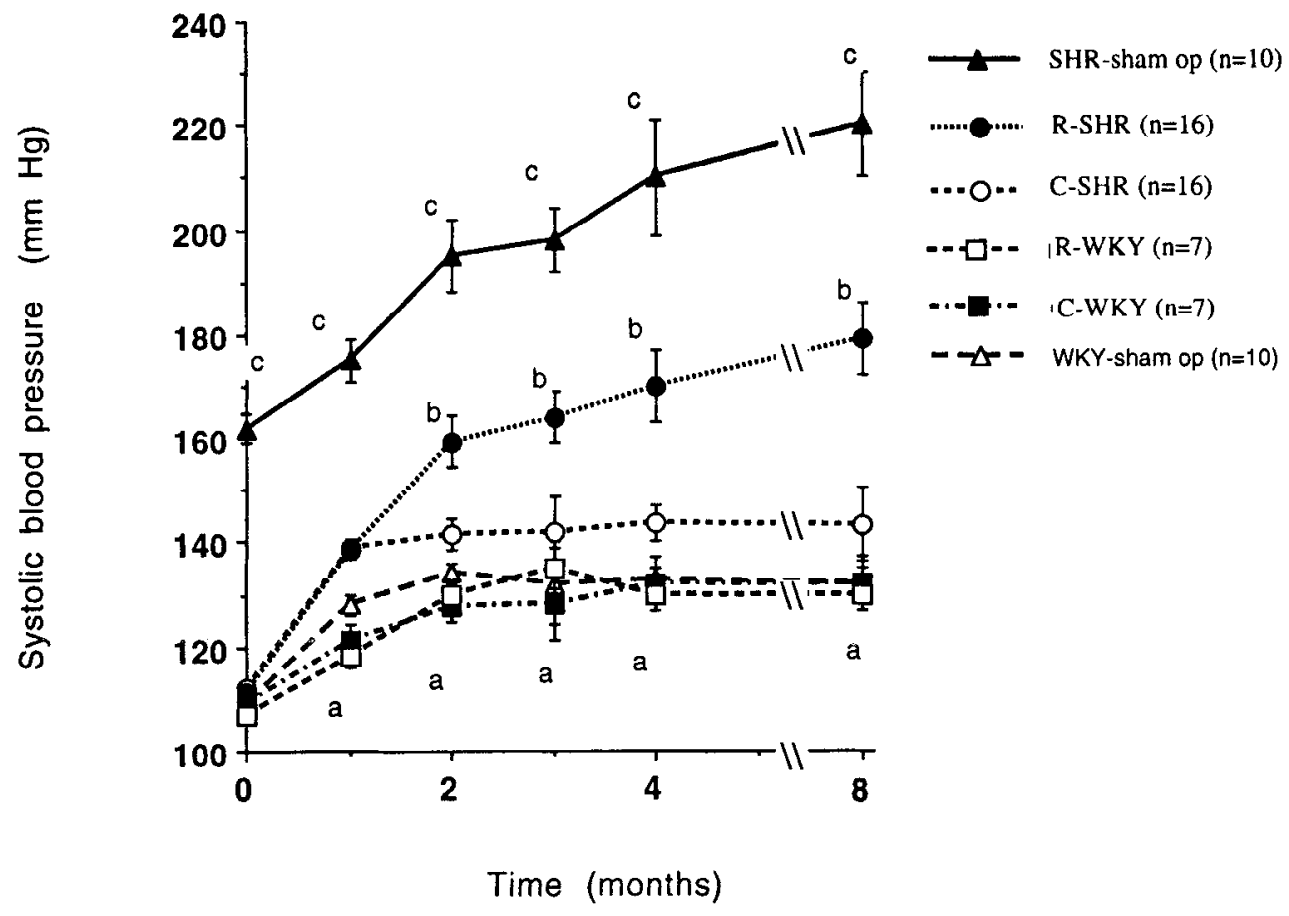

Table 1. Heart and kidney weight after implantation

\begin{tabular}{lll} 
& $\mathrm{Hw} / \mathrm{Bw} \times 100$ & $\mathrm{Kw} / \mathrm{Bw} \times 100$ \\
\hline S-SHR $(n=13)$ & $0.47 \pm 0.05^{*}$ & $0.69 \pm 0.05$ \\
S-WKY $(n=7)$ & $0.38 \pm 0.02$ & $0.72 \pm 0.03$ \\
R-SHR $(n=8)$ & $0.54 \pm 0.04^{*}$ & $0.81 \pm 0.08^{*}$ \\
C-SHR $(n=8)$ & $0.40 \pm 0.01$ & $0.69 \pm 0.01$ \\
R-WKY $(n-7)$ & $0.36 \pm 0.01$ & $0.70 \pm 0.02$ \\
C-WKY $(n=6)$ & $0.37 \pm 0.03$ & $0.71 \pm 0.01$
\end{tabular}

The table shows values of heart and kidney weight ( $\mathrm{H}$ Iw, Kw) normalized by body weight (Bw), 1 and 8 months, respectively, postimplantation in sham-operated spontaneously hypertensive rats (S-SHR), in sham-operated Wistar Kyoto rats (SWKY), in rats grafted with rostral or caudal hypothalamic tissue originating from spontaneously hypertensive rats (R-SHR and C-SHR, respectively), and in rats grafted with rostral or caudal hypothalamic tissue originating from WKY rats (RWKY and C-WKY, respectively) nificantly. The SBP recordings of the experiment and control groups (excluding those of the unilaterally grafted animals, which were similar to those of the controls) are depicted in Figure 3. Starting at 4 months, the animals grafted with rostral SHR HTH tissue only developed significantly higher SBP $(p<0.05)$ than rats in which whole HTH tissue had been implanted (Eilam et al., 1991).

Both heart and kidney weights were higher in the R-SHR group than in the control (Table 1). One month after grafting (i.e., before the onset of the rise in SBP), heart weight had already increased, whereas an elevation in kidney weight was noticed only 8 months postimplantation.

The immunohistochemical studies of the brain sections performed 3 months after implantation revealed the number of PVN VPi and THi cells in the WKY (C-WKY and R-WKY)

Table 2. Number of vasopressin-immunopositive (VPi) and tyrosine hydroxylase-immunopositive (THi) stained cells as a function of graft type and time

\begin{tabular}{|c|c|c|c|c|c|}
\hline \multirow[b]{2}{*}{$\begin{array}{l}\text { Post- } \\
\text { transplantation }\end{array}$} & \multicolumn{2}{|l|}{ PVN } & \multirow{2}{*}{$\begin{array}{l}\text { SCN } \\
\text { Parvo- } \\
\text { cellular } \\
\text { VPi }\end{array}$} & \multicolumn{2}{|l|}{ PVN } \\
\hline & $\begin{array}{l}\text { Magnocellular } \\
\text { VPi }\end{array}$ & $\begin{array}{l}\text { Parvo- } \\
\text { cellular } \\
\text { VPi }\end{array}$ & & $\begin{array}{l}\text { Magno- } \\
\text { cellular } \\
\mathrm{THi}\end{array}$ & $\begin{array}{l}\text { Parvo- } \\
\text { cellular } \\
\text { THi }\end{array}$ \\
\hline \multicolumn{6}{|l|}{3 months } \\
\hline R-SHR $(n=5)$ & $849 \pm 61^{a *}$ & $100 \pm 16^{\mathrm{b} *}$ & $831 \pm 41^{\mathrm{a} *}$ & $11 \pm 6^{a}$ & $526 \pm 17^{a}$ \\
\hline C-SHR $(n=5)$ & $595 \pm 102^{h *}$ & $404 \pm 63^{a *}$ & $857 \pm 123^{2}$ & $10 \pm 2^{a}$ & $499 \pm 27^{a}$ \\
\hline $\mathrm{WKY}(n=10)$ & $1078 \pm 17$ & $363 \pm 31^{a}$ & $920 \pm 72^{a}$ & $15 \pm 7^{\mathrm{a}}$ & $548 \pm 72^{a}$ \\
\hline \multicolumn{6}{|l|}{8 months } \\
\hline R-SHR $(n=5)$ & $251 \pm 68^{b}$ & $52 \pm 8^{c}$ & $452 \pm 48^{\circ}$ & $8 \pm 4^{a}$ & $512 \pm 12^{a}$ \\
\hline C-SHR $(n=5)$ & $217 \pm 15^{b}$ & $221 \pm 45^{b}$ & $504 \pm 35^{b}$ & $7 \pm 2^{a}$ & $533 \pm 14^{\mathrm{a}}$ \\
\hline WKY $(n=10)$ & $1039 \pm 50^{4}$ & $302 \pm 41^{a}$ & $828 \pm 54^{a}$ & $14 \pm 6^{\mathrm{a}}$ & $516 \pm 29^{a}$ \\
\hline
\end{tabular}

The superscript letters designate significantly different subgroups $(p<0.05)$ within each time group in each cell type. Asterisks indicate significant differences $(p<0.05)$ with time for the same animal group and same cell type (using Wilcoxon rank sum test). Data are means \pm SEM. R-SHR and C-SHR, Wistar Kyoto (WKY) rats grafted with rostral or caudal embryonic hypothalamic tissue originating from spontaneously hypertensive rats (SHR). WKY, control rats grafted with rostral or caudal hypothalamic tissue originating from WKY embryos. 

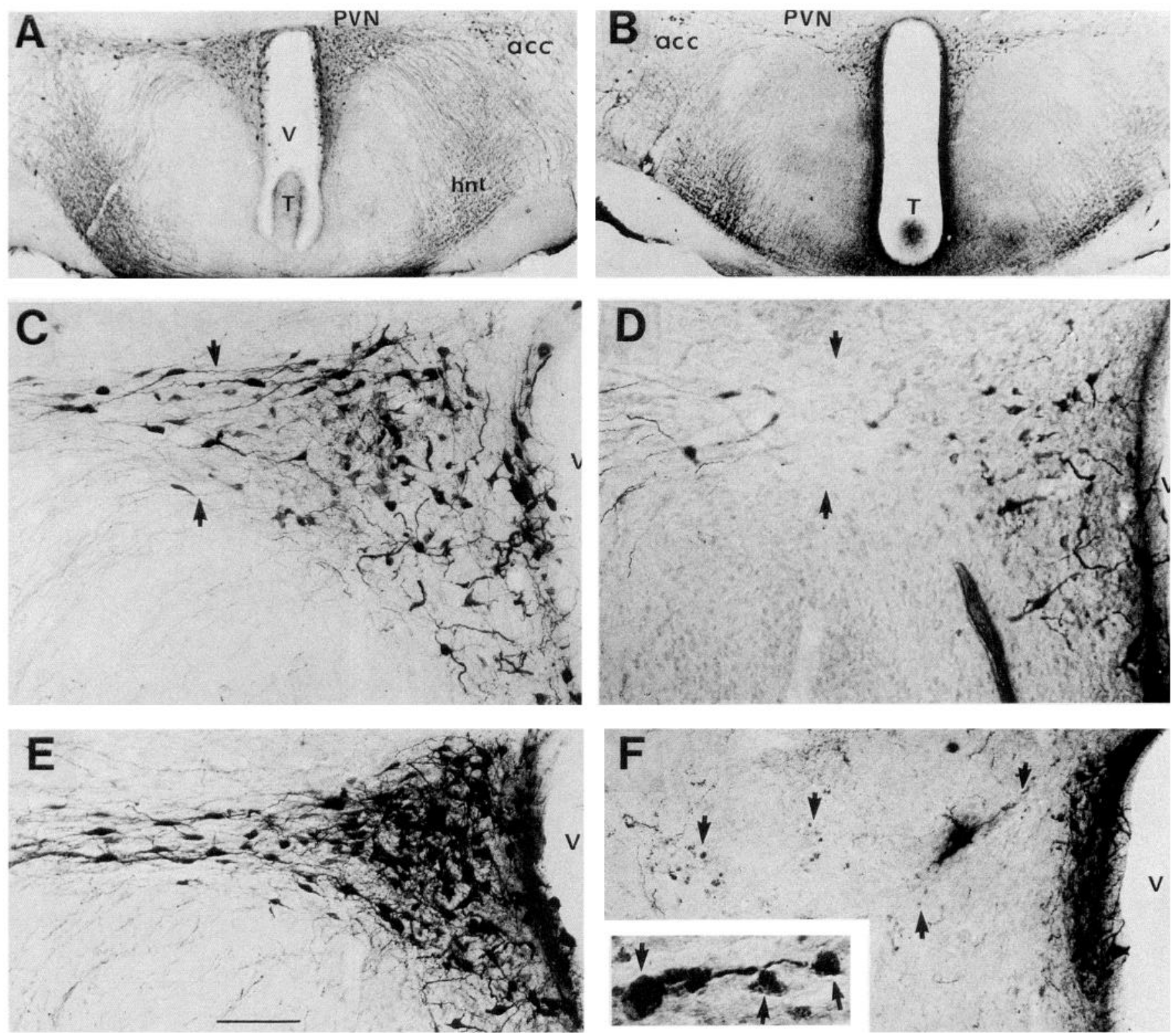

Figure 4. Transverse VPi-stained sections through two different levels $(A-D$ and $E-F)$ of the posterior PVN-an area consisting mainly of parvocellular cells-of control $(A, C, E)$ and experimental $(B, D, F)$ WKY rats, $2(A$ and $B)$ and $3(C-F)$ months postimplantation. $A$ and $B$, Low magnification of typical grafts $(T)$ located in the third ventricle $(V)$. $A$ shows graft of whole WKY hypothalamus tissue, and $B$ illustrates graft of rostral SHR hypothalamic tissue. Note attenuated VPi staining and reduction in volume and number of stained cells in the PVN area, the number of accessory neurons $(a c c)$ remaining unchanged. $C$ and $D$, High magnification of the PVN of rats grafted with rostral hypothalamic tissue taken from WKY $(C)$ or SHR $(D)$ embryos. The sections are at the same level as in $A$ and $B$; massive reduction in the number of VPi cells is seen in $D$. Arrows, borders of the nucleus as found by Nissl counterstaining. $E$ and $F$, High magnification of sections taken $100 \mu$ m caudally to the section in $C$ and $D$, respectively. $F$, Clusters of phagocyte-like cells (arrows) are visible within the PVN borders. Inset in $F$, High magnification (1000 $\times$ ) of phagocyte-like cells (containing VPi elements) surrounding a VPi fiber. acc, accessory neuron; hnt, hypothalamo-neurohypophysial tract; $P V N$, paraventricular nucleus. Scale bar $(E): 600 \mu \mathrm{m}$ for $A$ and $B, 120 \mu \mathrm{m}$ for $C-F$.

control groups to be consistent with that reported by Rhodes et al. (1981), Swanson et al. (1981), and Sawchencko and Swanson (1982). In the PVN of the R-SHR, substantial loss of VPi was noticed in various parvocellular $(\mathrm{P})$ neuron-containing regions (Table 2, Fig. 4); with loss was massive in the medial, dorsal, and lateral areas $(73 \%, 82 \%$, and $84 \%$, respectively; $p<0.001)$ and nonsignificant in the periventricular and anterior areas. At 3 months, no VPi P-neuronal loss was detected in the suprachiasmatic nucleus (SCN; Table 2). In the C-SHRs, there was a notable reduction in the number of VPi magnocellular (M) cells (Table 2). In the R-WKY and C-WKY, the number of VPi
P- and M-cells did not differ in comparison with the shamoperated WKY group. Unilateral grafting induced a massive loss of PVN VPi cells on the graft side but did not cause damage to the VPi cells of the adjacently located accessory nucleus (Fig. 5).

Eight months after transplantation, there was a striking disappearance of PVN VPi magnocellular cells in both R-SHR and C-SHR ( $76 \%$ and $79 \%$, respectively). The P-cells, on the other hand, decreased substantially $(82 \%)$ in the R-SHR, and only moderately (27\%), albeit significantly, in the C-SHR (Table 2). Interestingly, the number of VPi P-cells of the SCN at this stage 

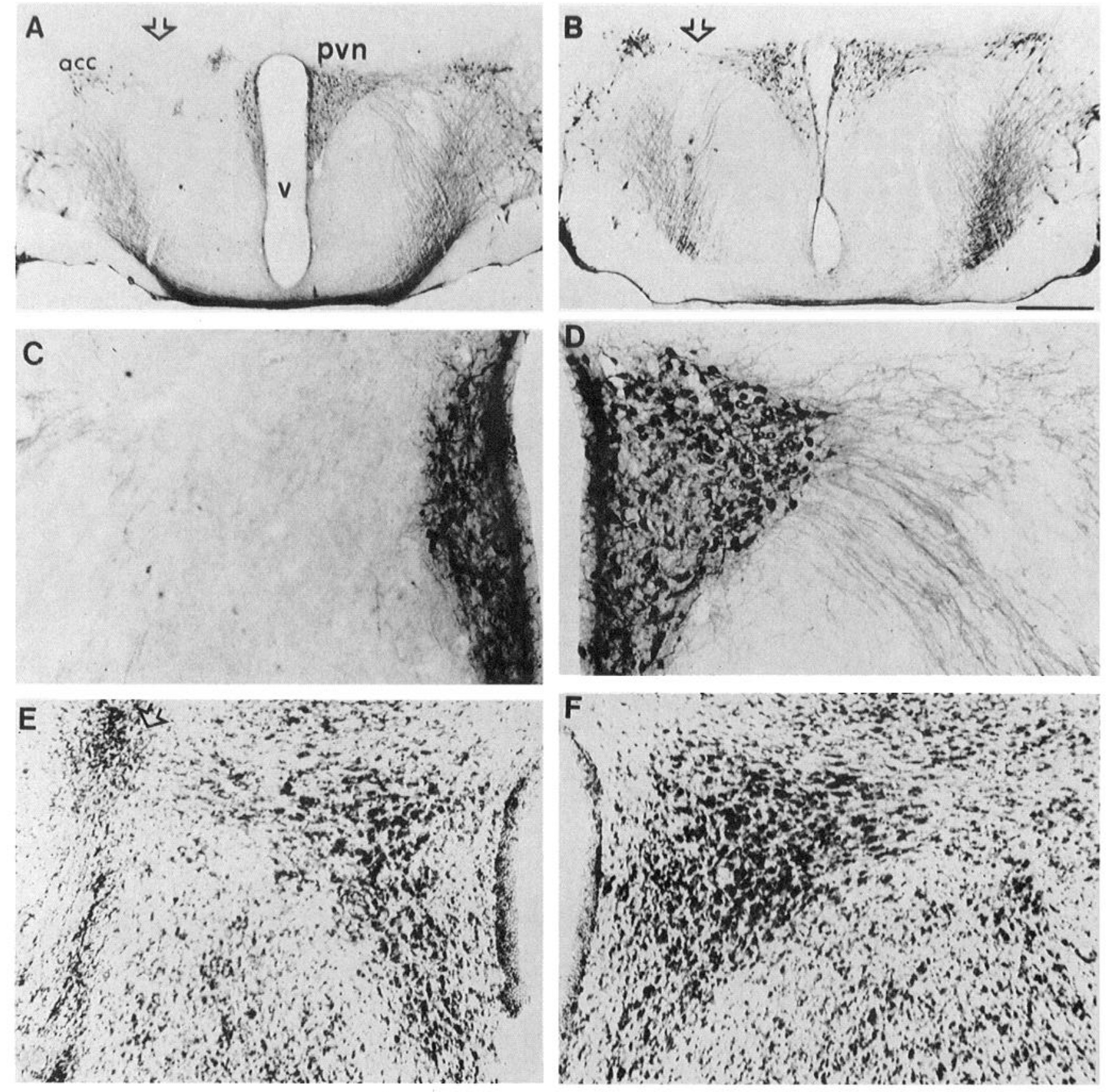

Figure 5. Unilateral effect (left hemisphere) of R-SHR graft implanted in the parenchymal tissue adjacent $(\sim 0.25 \mathrm{~mm})$ to the PVN of normotensive rat. Although the rostral $(A)$ and caudal $(B)$ grafts are located in the same hypothalamic region [about $1 \mathrm{~mm}$ lateral to the third ventricle $(V)$, in the intraparenchymal tissue], elimination of PVN parvocellular cells (but not of the accessory magnocellular cells, $a c c$ ) and enlargement of the third ventricle are seen only in $A$. $C$ and $D$, High magnification of left (C, grafted) and right $(D$, intact) hemisphere of an immunohistochemically VPstained section taken from a rostrally grafted animal; the section was located $100 \mu \mathrm{m}$ anterior to that displayed in $A$. Note massive reduction in number of VPi cells in the grafted hemisphere (left). $E$ and $F$, High magnification of Nissl-stained hemispheres $(E$, grafted; $F$, intact) in section located $100 \mu \mathrm{m}$ posterior to that displayed in $A$. Note moderate reduction in PVN cell population in the grafted hemisphere $(A, B$, and $E)$. Arrows point toward the needle track. Scale bar $(B): 600 \mu \mathrm{m}$ for $A$ and $B ; 180 \mu \mathrm{m}$ for $C-F$.

was also reduced in both experimental groups (Table 2). In contrast to the VPi cells, the OTi and THi (i.e., dopaminergic) cell populations were not affected by the rostral graft, as indicated by the lack of difference in PVN cell number between the experimental and control groups (Table 2, Fig. 2). Moreover, atrophy of the PVN and increase in third ventricle volume (Fig. 6) as well as shrinkage of extensive populations of cells in some PVN regions were clearly visible in the R-SHR-grafted animals.

To assess the degree of specificity of cell death, as indicated by loss of VPi cells (Lams et al., 1988), the sections were Nissl counterstained. Visual inspection of these sections showed a decrease in density of neuronal somata in regions of the PVN normally rich in VPi cells in both R-SHR and C-SHR. Cell counts in specific areas of the PVN of Nissl-stained sections revealed reduction in the number of somata in the posterior magnocellular region in the C-SHR group (by $26 \% ; p<0.01$ ) and in the dorsomedial and lateral parvocellular regions in the R-SHR (by $9.5 \%$ and $12 \%$, respectively; $p<0.05$ ), as compared 

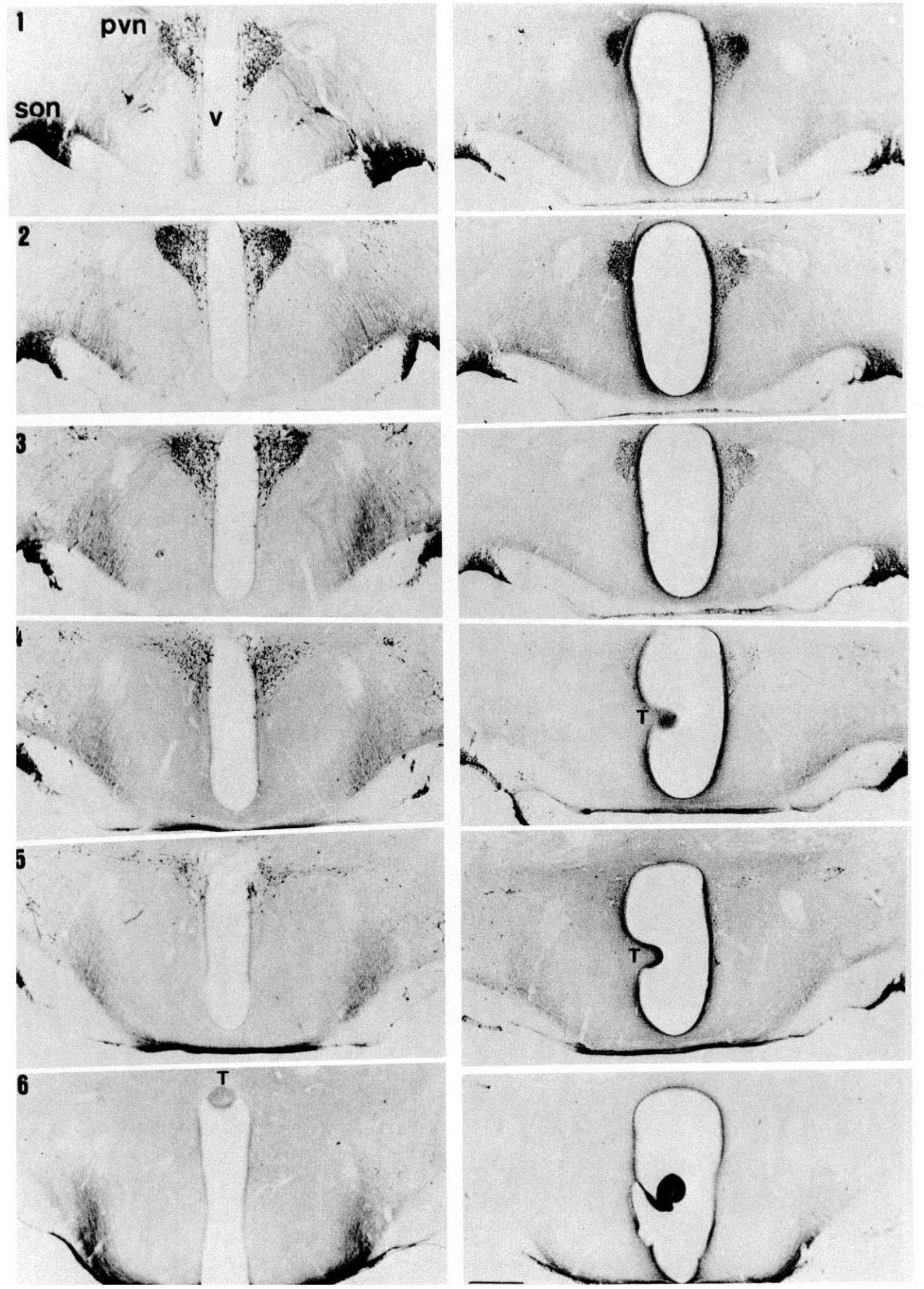

Figure 6. Vasopressin immunohistochemical staining of serial sections taken from the paraventricular level of rats 8 months after implantation. Left panels, Alternate sections taken from control (R-WKY) rat. Right panels, Alternate sections taken from experimental (R-SHR) rat. Atrophy of the PVN, reduced number of stained neurons, and enlargement of the third ventricle volume in the experimental group are clearly visible. Note attenuated selectivity toward magno- (sections 1-3) and parvocellular (sections 4 and 5) cells. pvn, paraventricular nucleus; son, suprachiasmatic nucleus; $T$, transplant; $v$, third ventricle. Scale bar, $500 \mu \mathrm{m}$. 

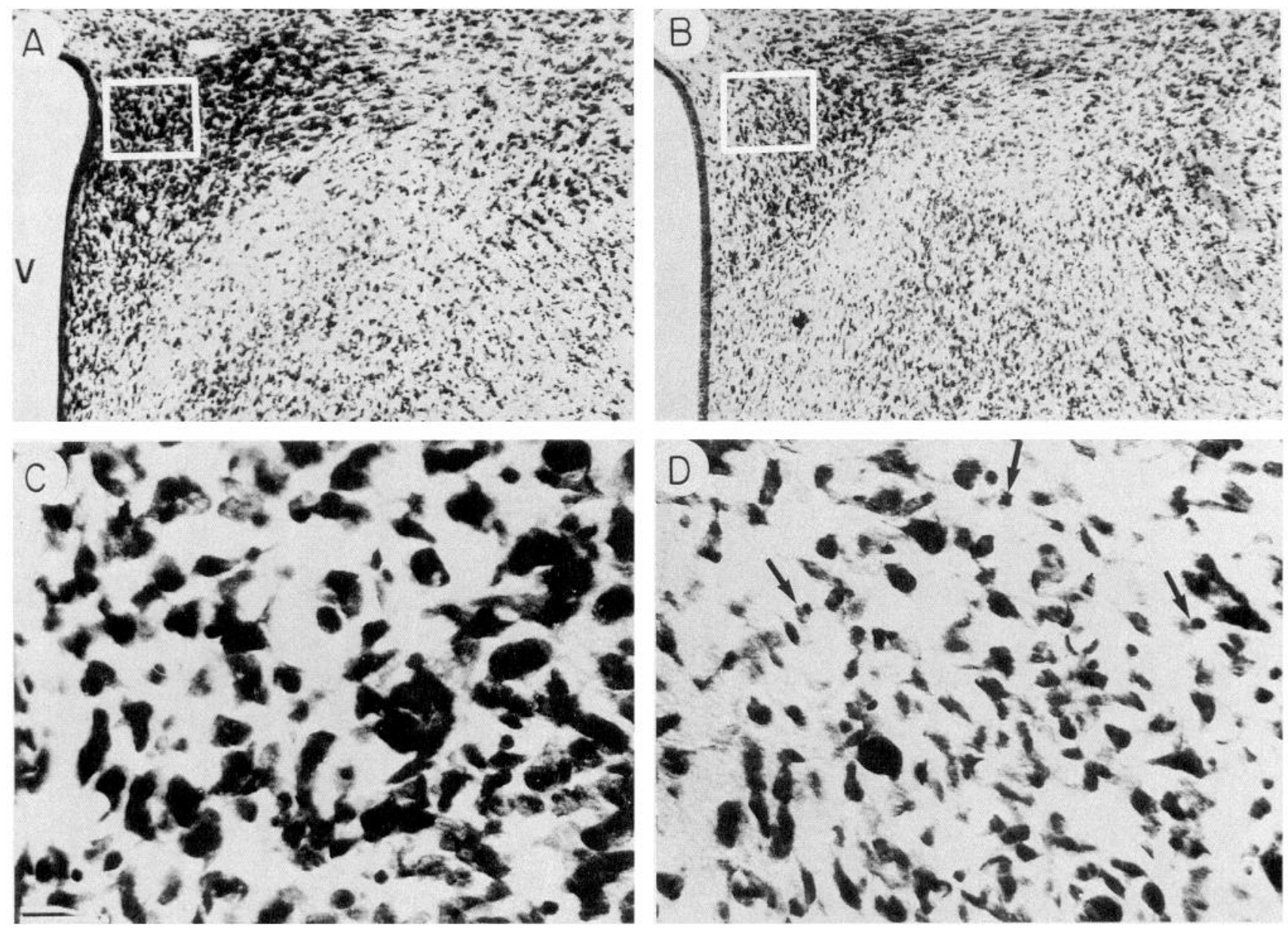

Figure 7. Bright-field photomicrograph of Nissl-stained coronal sections of grafted rats 8 months postimplantation. $A$ and $C$, Alternate sections taken from control (R-WKY) rat. $B$ and $D$. Alternate sections taken from experimental (R-SHR) rat. All sections were taken from parvocellular cell-rich areas, originating at the same level of the PVN. $A$ and $B$, Low magnification of paraventricular nucleus grafted rats. Boxed area represents dorsomedial parvocellular cells. $C$ and $D$, High magnification of boxed area. Cell shrinkage and reduction in cell number (108 vs 82 ) can be seen in the R-SHR (right) group compared to C-SHR (left). At this stage, the morphology structure of most of the cell population in the dorsal parvocellular region had changed. Arrows point toward shrinking cells. $V$, third ventricle. Scale bar $(C): 140 \mu \mathrm{m}$ for $A$ and $B, 20 \mu \mathrm{m}$ for $C$ and $D$.

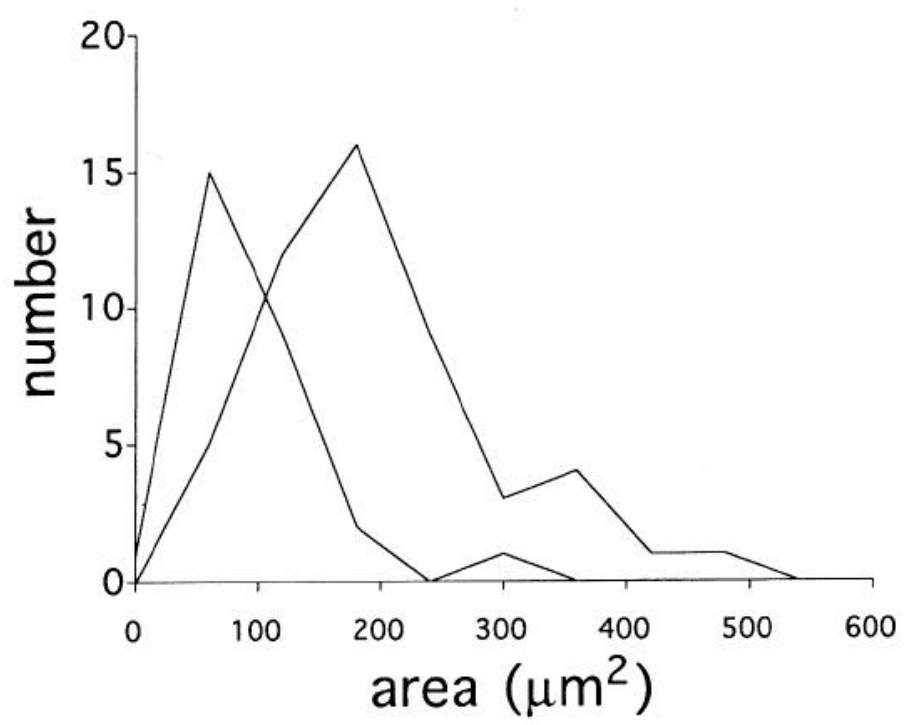

Figure 8. Frequency distribution of neuronal soma cross-sectional area of five serial sections originating in the P PVN region of a R-SHR (left histogram) and a R-WKY (right histogram) animal. with the controls (Fig. 7). Measurements of neuronal soma profiles of cross-sectional area from serial section of P VPi cells of the PVN region of an R-WKY and an R-SHR animal revealed reduction in cell number ( 89 vs 47$)$ as well as in cell area (226 $\pm 13 \mu \mathrm{m}^{2}$ vs $\left.127 \pm 10 \mu \mathrm{m}^{2}, p<0.0001\right)$ of VPi cells in the examined rat (Fig. 8). Furthermore, at 3 months, the VPi cells in the rostral graft had shrunk and were devoid of fibers (Fig. 1 ), as opposed to the our previous findings at 1 and 2 months of implantation (Eilam et al., 1991). Interestingly, OTi and THi cells in the grafted tissue wcre intact at 3 months of implantation, showing abundant sprouting of fibers (Figs. 1, 2).

Another method employed for the indication of cell death after transplantation is the TUNEL stain; it involved labeling of DNA ends in situ with BiUTP via terminal transferase (Gavrieli et al., 1992) for visualization of programmed cell death (apoptosis) at single-cell level. The staining revealed a clear pattern of nuclear staining. The fragmented nuclei are similar to those seen with the intercalating DNA dye DAPI in tissue culture (Abbadie et al., 1993). A striking and selective staining of cells in the PVN region mainly in the lateral and medial $\mathrm{P}$ areas, but not in the PVN periventricular or neighboring areas in R-SHR, was seen (Fig. 9). 
A
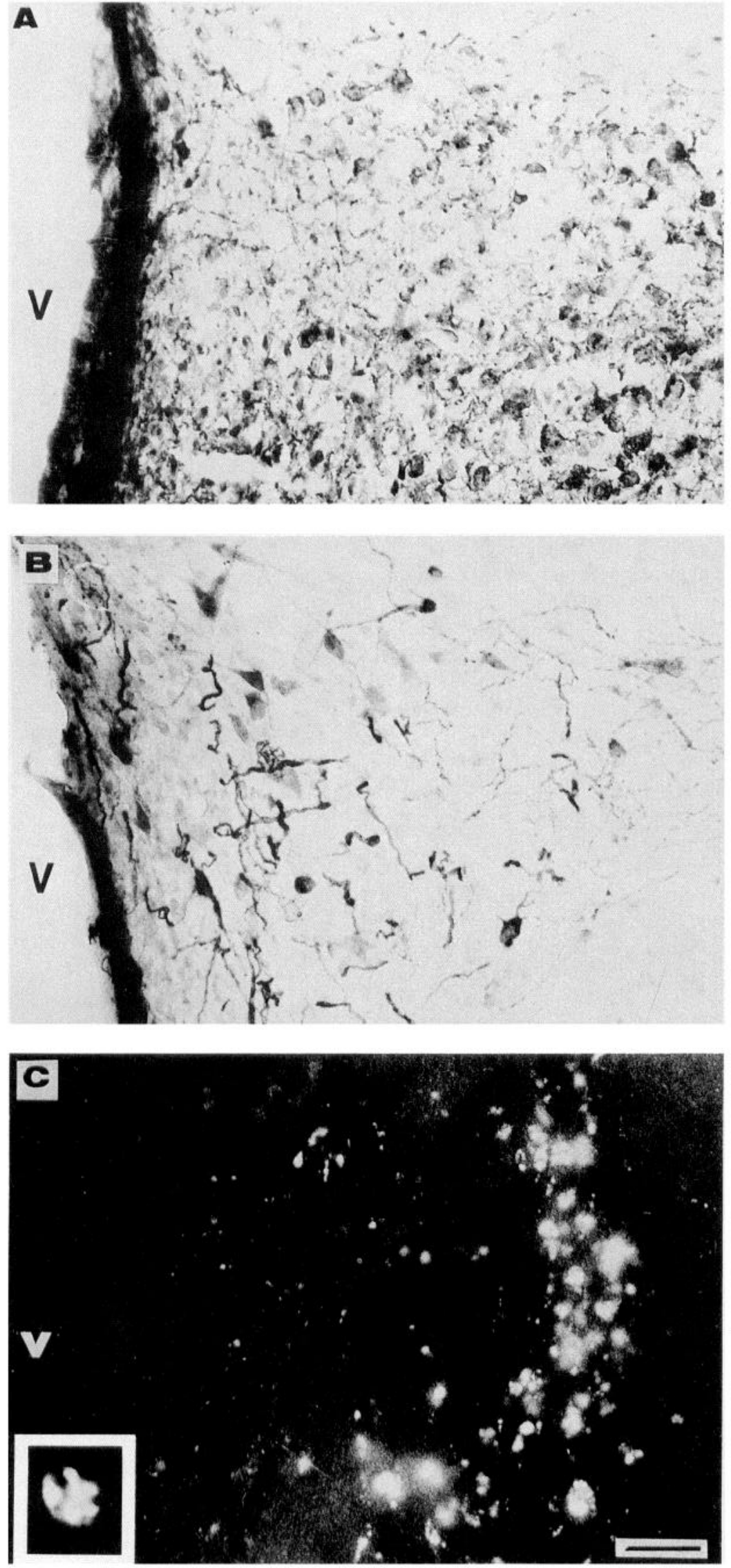

Figure 9. Serial sections taken from R-SHR rat (at the PVN $\mathrm{P}$ level) 3 months after implantation. $A$ and $B$, Immunopositive staining for OT and VP, respectively. $C$, TUNEL staining. $A$, No damage to OT-immunopositive cells could be observed in the PVN. $B$, Massive loss in VP-immunopositive staining in the same region as in $A$. $C$, TUNEL staining indicates cell death mainly in the lateral region of the PVN. Inset, High magnification $(1000 \times)$ of a cell undergoing programmed cell death. $V$, third ventricle. 


\section{Discussion}

In recent years, an extensive network of extrahypothalamic VPand OT-containing neurons has been identified within the CNS (Sofroniew and Schrell, 1981; Sawchenko and Swanson, 1982). Some of these peptidergic fibers appear to terminate in areas of the brainstem and spinal cord that are known to be involved in the regulation of cardiovascular functions. The origin of the majority of these fibers seems to be in the hypothalamic PVN. Although the function of VP in the brainstem has not yet been clarified, it has been suggested that this peptide participates in the control of the baroreceptor reflex (BRR) as neuromediator, eventually producing a decrease in heart rate and cardiac output (Montany et al., 1980). VP acting as neuromediator would be consistent with phenomena observed in different studies. Thus (1) microinjections of VP to brainstem nuclei altered profoundly neuronal firing frequency and caused reduction in BP and heart rate when applied to the rat brainstem region (Morris et al., 1980; Matsuguchi et al., 1982); (2) reduction in VP levels in the CNS of adult hypertensive rats (SHR), particularly in the PVN and brainstem, occurred concomitantly with a decrease in BRR activity (Judy et al., 1979; Mohring et al., 1981); (3) evidence gathered in humans and animals suggests that even plasma VP concentrations within physiological range may elevate $\mathrm{BP}$ in cases in which the compensatory role of the BRR is impaired (Montani et al., 1980; Mohring et al., 1981).

There is little information about the role of the central OT in $\mathrm{BP}$ regulation, although immunohistochemical studies have shown that there are more OT than VP fibers $(4: 1)$ in the brainstem (Sofroniew and Schrell, 1981; Swanson and Sawchenko, 1983).

In a previous study we found that transplantation of whole hypothalamic tissue taken from SHR embryos induces hypertension in the hosts (Eilam et al., 1991). The present study confirms and extends this observation by showing that rostral, but not caudal, HTH produced a severe risc in SBP in the grafted animals, demonstrating that the pathological factors involved in the transplantation effect show regional specificity in the HTH. Consistent with this finding was the observation that transplanted whole (Eilam et al., 1991) HTH tissue exerted a weaker influence on SBP than the rostral part of the HTH alone, not withstanding the comparable size of the grafts.

The development of hypertension in the SHR strain has been reported to occur concomitantly with degeneration of various brain regions, including the PVN (Nelson and Boulant, 1981). In the present study, the profound elimination of VPi P-cells in the PVN of the rostrally grafted rats (R-SHR) 3 months postoperatively (particularly in the dorsal and lateral regions, which project mainly to the spinal cord or to the brainstem; Figs. 4, 9) coincident with an increase in SBP (Fig. 3). Specific reduction in VP content in the PVN of SHRs has been reported (Lang et al., 1981; Morris and Keller, 1982), findings that are compatible with preliminary studies in our laboratory (R. Eilam, unpublished observations), which showed that in the PVN of intact mature (2-8 months) SHRs a gradual diminution of the VPi $\mathrm{P}$-cells takes place, followed by a reduction in VPi M-cells (at 6-12 months). On the other hand, in rats with peripherally induced hypertension, the number of VPi cells (Eilam, unpublished observations), as well as VP levels (Sladek et al., 1988), remained unchanged. It seems reasonable to assume, therefore, that the large reduction in VPi P-cells, as observed in the R-SHR, was a contributory factor in the development of hypertension (and not vice versa). In the C-SHR, the magnitude of VPi P degeneration 8 months postimplantation was presumably too small to affect SBP. This proposition seems plausible in view of the fact that unilateral grafting failed to alter the SBP. The lack of effect of the unilateral grafting on BP may be ascribed to noninterference with the contralateral hemisphere, thus allowing extensive survival of its VPi PVN cells (Fig. 5).

The high blood pressure in intact SHR may result from imbalance between the neuronal (parvocellular) and hormonal (magnocellular) components of the VP system (Unger et al., 1986) or, quite likely, may be due to a disequilibrium between the VP and other systems (Palkovits and Zaborszky, 1977; Olpe and Baltzer, 1981; Unger et al., 1984) including OT. This situation differs from that in the normotensive Brattleboro rat developed by Valtin (1967) in which neither type of cell produces VP. The reported finding that SHR-diabetes-insipidus rats (a crossbreed between spontaneously hypertensive and Brattleboro rats) develop genetic hypertension despite little or no detectible brain or plasma VP (Ganten et al., 1983) is in keeping with the hypothesis that in the SHR strain (which is characterized by broad spectrum of deviations) discordance between central VP and other pressor systems may contribute to the hypertension. In the R-SHR, BP increased steadily during the 8 experimental months. On the other hand, the BP of the C-SHR rose only during the first month postimplantation, thereafter showing a plateau at a level significantly lower than that of the R-SHR group. According to the histological evidence, 3 months after implantation the elevation in BP in the R-SHR was accompanied by an alteration in the ratio between $M$ and $P$ VP cells of the paraventricular nucleus, in that the relative number of $M$ cells increased, whereas in the C-SHR the ratio between these two types of cells was reversed. It is therefore logical to assume that the PVN P-cells are critical for BP control. We suggest that the graft-induced imbalance in VP activity may thus be the cause for the elevated BP observed in our R-SHR model.

The reduction of VPi P cells - but not of OTi or THi P cellsin the PVN (Fig. 2, Table 2) suggests the adverse effects of rostral grafts to be cell specific. This, in turn, presents the intriguing possibility that the mechanism underlying the elimination of $P$ cells may be a neurotoxic action of substance-induced overactivation (e.g., by glutamate) toward this type of cells (Herman and Wiegand, 1986; Choi et al., 1987; Garthwaite and Garthwaite, 1990; Rockhold et al., 1990; Bredt and Snyder, 1992).

Phagocytes, which accompany cell death in the CNS, have been reported in the normal developing brain (a period of naturally occurring massive cell death), in adult human brains in neurological diseases (e.g., Alzheimer, Parkinson; McGeer et al., 1988; Milligan et al., 1991), and in the initial stages of a certain type of cell death (Beaulaton and Lockshin, 1982; Markram and Segal, 1990; Finch, 1993). The presence of phagocytelike and pyknotic cells (Fig. 4), in conjunction with shrinkage of cells 3 months postimplantation (Fig. 8), as well as of apoptotic cells (Fig. 9), is strongly indicative of a degenerative process in the PVN of R-SHR. Moreover, the massive loss and shrinkage of PVN cells 3 and 8 months postimplantation may very well have contributed to the dilation of the third ventricle in the grafted animals (Fig. 6). A comparable ventricular dilation associated with reduced brain weight and volume has been found in adult SHR (Ritter et al., 1988; Bendel and Eilam, 1992).

The hypertrophy of the heart noticed before SBP started to rise, and that of the kidneys starting 6 months after onset of the 
increase in SBP in the R-SHR are aberrancies that have been reported previously in the native SHR (aged 1 month and $>18$ months, respectively) (Feld et al., 1977; Eccleston-Joyner and Gray, 1988). These time-related events may indicate involvement of the rostral HTH in the pathogenesis of these organs (Jin and Rockhold, 1989), which in turn may contribute to the long-term elevation of the SBP in the R-SHR. It should be noted that long-term regulatory mechanisms that act to balance arterial $\mathrm{BP}$ are mostly related to kidney function. It is conceivable that the long-term hypertension induced by the rostral tissue may be partly due to a deleterious effect of the HTH on the kidney, a claim that is supported by the hypertrophy of this organ in such grafted animals.

In summary, the present data suggest that the rostral and caudal hypothalamic regions of the SHR induce distinct patterns of PVN neuronal (magno- or parvocellular VPi cells) loss in a time-dependent manner. The mechanism by which the rostral SHR graft elevates SBP is not yet clear, although it seems plausible that reduction in neuronal VP as a result of the elimination of parvocellular PVN VPi cells impairs BBR function, a process that plays a prime role in short-term blood pressure regulation. Resetting of this reflex is an important contribution to the longterm adjustment of SBP.

\section{References}

Abbadie C, Kabrum N, Bouali F, Samardova J, Stehelin D, Vanderbunder V, Enrietto PJ (1993) High levels of c-rel expression are associated with programmed cell death in the developing avian embryo and bone marrow cells in vitro. Cell 75:899-912.

Abercrombie M (1946) Estimation of nuclear population from microtome sections. Anat Rec 94:239-247.

Beaulaton J, Lockshin RA (1982) The relation of programmed cell death to development and reproduction: comparative studies and an attempt at classification. Int Rev Cytol 79:215-235.

Ben-Barak Y, Russell JT, Whitnall MH, Ozato K, Gainer H (1985) Neurophysin in the hypothalamo-neurohypophysial system. I. Production and characterization of monoclonal antibodies. J Neurosci 5:81-97.

Bendel P, Eilam R (1992) Quantitation of ventricular size in normal and spontaneously hypertensive rats by magnetic resonance imaging. Brain Res 574:224-228.

Bredt DS, Snyder SH (1992) Nitric oxide, a novel neuronal messenger. Neuron 8:3-11.

Choi DW, Maulucci-Gedde M, Kriegstein AR (1987) Glutamate neurotoxicity in cortical cell culture. J Neurosci 7:357-368.

Ciriello J, Calaresu FR (1980) Role of paraventricular and supraoptic nuclei in central cardiovascular regulation in the cat. Am J Physiol 239:R137-R 142.

Eccleston-Joyner CA, Gray SD (1988) Arterial hypertrophy in the fetal and neonatal spontaneously hypertensive rat. Hypertension 12:513518.

Eilam R, Malach R, Bergmann F, Segal M (199l) Hypertension induced by hypothalamic transplantation from genetically hypertensive to normotensive rats. J Neurosci 11:401-411.

Feld LG, Van Liew JB, Galaske RG, Boylan JW (1977) Selectivity of renal injury and proteinuria in the spontaneously hypertensive rat. Kidney Int 12:332-343.

Finch CE (1993) Neuron atrophy during aging: programmed or sporadic? Trends Neurosci 16:104-110.

Fukushima M (1968) Histometric and histochemical studies of the hypothalamo-hypophysial system of spontaneously hypertensive rats and rats with experimental hypertension. Jpn Circ I 33:485-516.

Ganten U, Rascher W, Lang RE, Dietz R, Retting G, Unger T, Taugner R, Ganten D (1983) Development of new strain of spontaneously hypertensive rats homozygous for hypothalamic diabetes. Hypertension 5:1119-1128.

Garthwaite J, Garthwaite G (1990) Mechanisms of excitatory amino acid neurotoxicity in rat brain slices. Adv Exp Med Biol 268:505518 .
Gavrieli Y, Sherman Y, Ben-Sasson SA (1992) Identification of programmed cell death in situ via specific labeling of nuclear DNA fragmentation. J Cell Biol 119:493-501.

Herman JP, Wiegand SJ (1986) Ibotenate-induced cell death in the hypothalamic paraventricular nucleus: differential susceptibility of magnocellular and parvicellular neurons. Brain Res 383:367-372.

Jin CB, Rockhold RW (1989) Effects of paraventricular hypothalamic microinfusions of kainic acid on cardiovascular and renal excretory functions in conscious rats. J Pharmacol Exp Ther 25:1969-1975.

Judy WJ, Watanabe AN, Murphy WM, Apprison BS, Yu PL (1979) Sympathetic nerve activity and blood pressure in normotensive backcross rats genetically related to the spontaneously hypertensive rats. Hypertension 1:598-604.

Lams BE, Isacson O, Sofroniew MV (1988) Loss of transmitter-associated enzyme staining following axotomy does not indicate death of brainstem cholinergic neurons. Brain Res 475:401-406.

Lang RE, Rascher W, Unger T, Ganten D (1981) Reduced content of vasopressin in the brain of spontaneously hypertensive as compared to normotensive rats. Neurosci Lett 23:199-202.

Markram H, Segal M (1990) Regional changes in NGF receptor immunohistochemical labeling in the septum of the aged rat. Neurobiol Aging 11:481-484.

Matsuguchi H, Sharaki FM, Gordon FJ, Johnson AK (1982) Blood pressure and heart rate response to mini-injections of vasopressin into the nucleus tractus solitarius region in the rat. Neuropharmacology 21:687-693.

McGcer PL, Itagaki S, McGcer EG (1988) Expression of the histocompatibility glycoprotein HLA-DR in neurological disease. Acta Neuropathol (Berl) 76:550-557.

Meyer JM, Felten DL, Weyhenmeyer JA (1990) Measurement of immunoreactive angiotensin II levels in microdissected brain nuclei from developing spontaneously hypertensive and Wistar Kyoto rats. Exp Neurol 107:164-169.

Milligan CE, Cunningham TJ, Levitt P (1991) Differential immunochemical markers reveal the normal distribution of brain macrophages and microglia in the developing rat brain. J Comp Neurol 314:125-135.

Montany JP, Liard JF, Schoun J, Mohring J (1980) Hemodynamic effect of exogenous and endogenous vasopressin at low plasma concentrations in conscious dogs. Circ Res 47:346-355.

Morris M, Keller M (1982) A specific deficiency in paraventricular vasopressin and oxytocin in the spontaneously hypertensive rat. Brain Res 249:173-176.

Morris M, Ross J, Sundberg DK (1985) Catecholamine biosynthesis and vasopressin and oxytocin secretion in the spontaneously hypertensive rat: an in vitro study of localized brain regions. Peptides 6:949955

Morris R, Salt TE, Sofroniew MV, Hill RG (1980) Action of microiontophoretically applied oxytocin, and immunochemical localization of oxytocin, vasopressin and neurophysin in the rat caudal medulla. Neurosci Lett 18:163-168.

Murphy CA, Yongue BG, Cheng J, Skaredoff L (1991) Cardiovascular and behavioral effect of fetal hypothalamic grafts in hypertensive and normotensive rats. Soc Neurosci Abstr 17:997.

Nagaoka A, Lovenberg W (1977) Regional changes in the activities of aminergic biosynthetic enzymes in the brain of hypertensive rats. Eur J Pharmacol 43:297-306.

Nelson DO, Boulant JA (1981) Altered CNS neuroanatomical organization of spontaneously hypertensive (SHR) rats. Brain Res 226: 119-130.

Olpe HR, Baltzer V (1981) Vasopressin activates noradrenergic neurons in the rat locus coeruleus: a microiontophoretic investigation. Eur J Pharmacol 73:377-378.

Palkovits M, Zaborszky L (1977) Neuroanatomy of the central cardiovascular control. Nucleus tractus solitarii: afferent and efferent neuronal connections in relation to the baroreceptor reflex arc. Prog Brain Res 47:9-34.

Rhodes CH, Morrell JI, Pfaff DW (1981) Immunohistochemical analysis of magnocellular elements in rat hypothalamus. Distribution and numbers of cells containing neurophysin, oxytocin, and vasopressin. J Comp Neurol 198:45-64.

Ritter S, Dinh TT, Stone S, Ross N (1988) Cerebroventricular dilation in spontaneously hypertensive rats (SHR) is not attenuated by reduction of blood pressure. Brain Res 450:354-359.

Rockhold RW, Acuff CG, Clower BR (1990) Excitotoxic lesions of 
the paraventricular hypothalamus: metabolic and cardiac effects. Neuropharmacology 29:663-673.

Sawchenko PE, Swanson LW (1982) Immunohistochemical identification of neurons in the paraventricular nucleus of the hypothalamus that project to the medulla or to the spinal cord in the rat. J Comp Neurol 205:260-272.

Sladek CD, Devine MA, Felten SY, Aravich PF, Blair ML (1988) Abnormalities in hypothalamic and neurohypophysial vasopressin content are not a consequence of hypertension in the spontaneously hypertensive rat. Brain Res 445:39-46.

Sofroniew MV, Schrell U (1981) Evidence for a direct projection from oxytocin and vasopressin neurons in the hypothalamic paraventricular nucleus to the medulla oblongata: immunohistochemical visualization of both the horseradish peroxidase transported and the peptide produced by the same neurons. Neurosci Lett 22:211-217.

Swanson LW, Sawchenko PE (1983) Hypothalamic integration: organization of the paraventricular and supraoptic nuclei. Annu Rev Neurosci 6:269-324.

Swanson LW, Sawchenko PE, Berod A, Hartman BK, Helle KB, Vanorden DE (1981) An immunohistochemical study of the organiza- tion of catecholaminergic cells and terminal fields in the paraventricular and supraoptic nuclei of the hypothalamus. J Comp Neurol 196:271-285.

Unger T, Rohmeiss P, Becker H, Ganten D, Lang RE, Petty MA (1984) Sympathetic activation following central vasopressin stimulation in conscious rats. J Hypertens 2:25-27.

Unger '1, Kohmeiss P, Demmert G, Ganten D, Lang RE, Luft FC (1986) Differential modulation of the baroreceptor reflex by brain and plasma vasopressin. Hypertension 8:157-162.

Valtin H (1967) Hereditary hypothalamic diabetes insipidus in rats (Brattleboro strain). A useful experimental model. Am J Med 42:814827.

Winternitz SR, Wyss JM, Oparil S (1984) The role of the posterior hypothalamic area in the pathogenesis of hypertension in the spontaneously hypertensive rat. Brain Res 324:51-58.

Xiao YF, Brezenoff HE (1988) The role of M2 muscarinic receptors in the posterior hypothalamus in the pressor response to intracerebroventricularly-injected neostigmine. Neuropharmacology 27:10611065. 